\title{
Shadow Play Application in Children’s Wear Design
}

\author{
Yu Yang ${ }^{1 *}$ \\ ${ }^{1}$ Sino-French Institute of Fashion Designer, Shanghai University of Engineering Science, Shanghai, \\ China \\ *Yu Yang, E-mail: yangyu19930601@163.com
}

Received: October 30, 2017 Accepted: November 28, 2017 Online Published: November 30, 2017

doi:10.22158/wjssr.v4n4p385 URL: http://dx.doi.org/10.22158/wjssr.v4n4p385

\begin{abstract}
In the mother of traditional culture, folk traditional handicraft is rich in content and various kinds, because of various artistic expression form and the artistic expression style that has visual effect is unique. As a kind of ancient Chinese folk traditional art, shadow play is famous for its rich traditional Chinese cultural patterns, unique color combination and retro characters.

Nowadays, the growth of children's clothing market is especially bright in the market of adult clothing. But whether it is the children's clothing derived from the foreign brands, or the brand that has been the market base in China for many years, the children's clothes style is single, and the type of printing is not new. This research will use the performance of shadow play in children's clothing, aiming to make children's clothing with traditional Chinese elements.
\end{abstract}

\section{Keywords}

Shadow Play, figure costume modeling, fabric modification

\section{Introduction}

Shadow Play art has a long history, it has deposited rich cultural connotation after all ages. It was a recreational activity for leisure in the early days, and later it became a valuable handicraft. As an important part of Chinese traditional culture, Shadow Play has profound historical and cultural connotation and the folk auspicious meaning, and it is the Chinese national culture treasure. However, as time goes by, there are not so many people know the art, and less learning about it. Apply the Shadow Play expression manners in designing children's wear, on one hand, children and parents can know or even understand the shadow play; on the other hand, the Shadow Play elements are put into the present generation design, aims to create new clothing products, which is not only a Shadow Play art value embodiment in clothing culture, but also new national concept embodiment in modern clothing. 


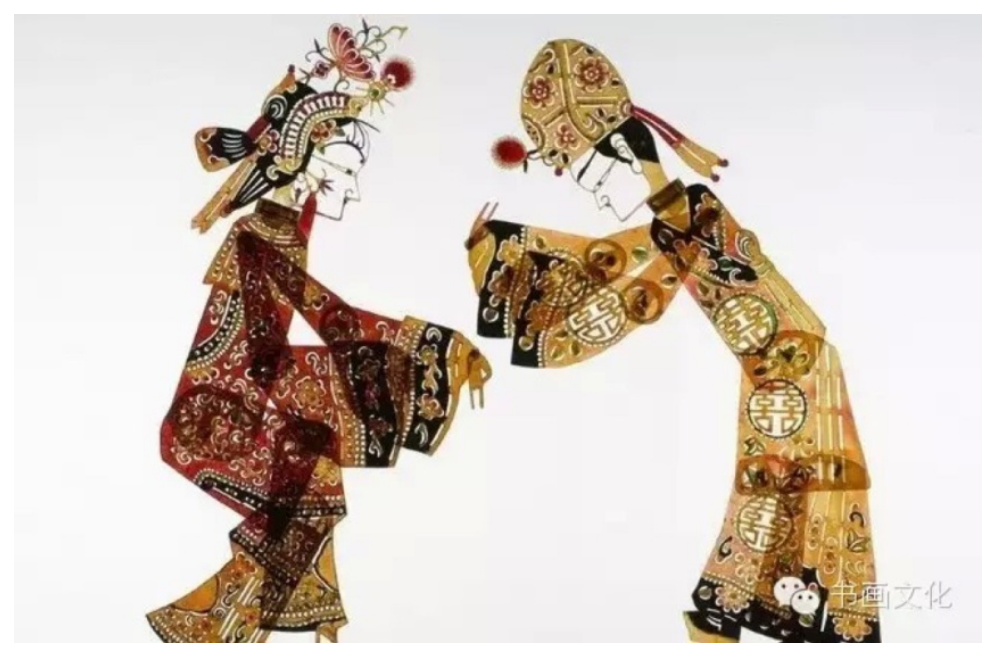

Figure 1. Character Models in Shadow Play

According to the topic, the study content is mainly detailed at two ways: Shadow Play and children's wear. Shadow Play has a long history, it is the treasure of Chinese traditional culture, since many elements have the times sense of the times and can be popular. The element lacks fashion sense which is keeping pace with the times, so the most important is to extract this very representative element when studying Shadow Play, and apply and transform the element to inject fashion into and enhance, and promote emperament temperament on the basis of preserving its essence.

The innovation in choosing topic is mainly as followed:

First, is the style design, now most children wear has single style on the market. Traditional "princess skirts" will be accepted, but lack of new ideas, the Chinese style is also somewhat alien. So the focus is to introduce new styles, put the narrow-wide profile of the silhouette into designing clothes, and make clothes version "Shadow-Play like".

The next is the fabric transformation. In the printed pattern clothes, use colored lines or beads to decorate the local pattern. Alternatively, attach another same layer pattern to express a three-dimensional effect.

\section{Method}

In order to perfectly complete the production process, we to support the study with the following research methods obtaining relevant data or materials:

1) Literature Analysis: focus on the research direction, we search and read a large number of related literatures and analyze them, and the conclusions are summarized. These literatures will provide a solid and systematic theoretical support for the study.

2) Cultural Investigation: Cultural investigation are mainly divided into two parts. On one hand, every year there will be many children's clothing brand fashion shows on Fashion Week, we can grasp the 
fashion trends through accurate viewing these shows. The information keep clothes more in line with fashion trend and advance with the times. For the previous children's wear show, you can watch videos on the Internet. On the other hand, you can watch exhibitions, aiming at the research direction, mainly two themes shows are suitable. One is the clothing element, you can understand the origin and the development of fashion clothes and the design will inspire you. The other is something related to Shadow Play, information on the network can only be used as reference, you can have more close contact contact Shadow Play through the exhibitions, so as to observe more details and apply it in clothing.

3) Market Research. For this theme, the research focuses on going to all kinds of children's clothing brand stores, and seeing the clothes style, texture and printing type. If there are no physical stores surrounding, you enter their official website to learn their clothes styles and materials. There is also a very important place for research is the children's clothing wholesale market, the markets can be the most intuitive observation places, you can know various demand styles. Besides children's ware, you also need to understand the use of Chinese elements in clothes, whether in foreign advanced custom brand or domestic local brand. Make a summary, learn from where it is worth learning, and make analogy.

According to the characteristics of the Shadow Play, extract the appropriate parts of and combine them with designing clothes, the design plans are as followed:

1) Profile Application. Use the "narrow and wide" feature in shadow puppetry, by shrinking the shoulders, enlarging the dress or trouser legs to form a visual sensation, which is expressed as up small and down large. Also, without changing the narrow wide premise, shrink the waist to highlight the clothing lines.

2) Fabric Apply. The Shadow Play is made of sheepskin, donkey skin as based skins. The audience group are children, but the fabric is not directly used to contact with children's skin. Then cotton, silk and polyester fiber are the first choice for clothing fabrics. But in order to respond to the theme, the artificial leather is cut, hollowed out or spliced as the details to decorate clothes.

3) Color Apply. The color principle lies at the five Elements in civil attention: red, yellow, white, blue, black. Yellow is the color of the leather, and the white is the yarn. So during this design, we plan white as the main color, and the shadow printings are mainly colored with red, blue, black.

4) Pattern Apply. Patterns can be used in two ways, one is decorating all types overall image directly on the clothes cuff, neckline or waist and other places. The other way is using shadow play graphics. Shadow play graphics contain a lot of folklore, and the folklore is often expressed through people's faith to the totem or folk mascot, combine and splic such graphics to make printing on the clothes. 


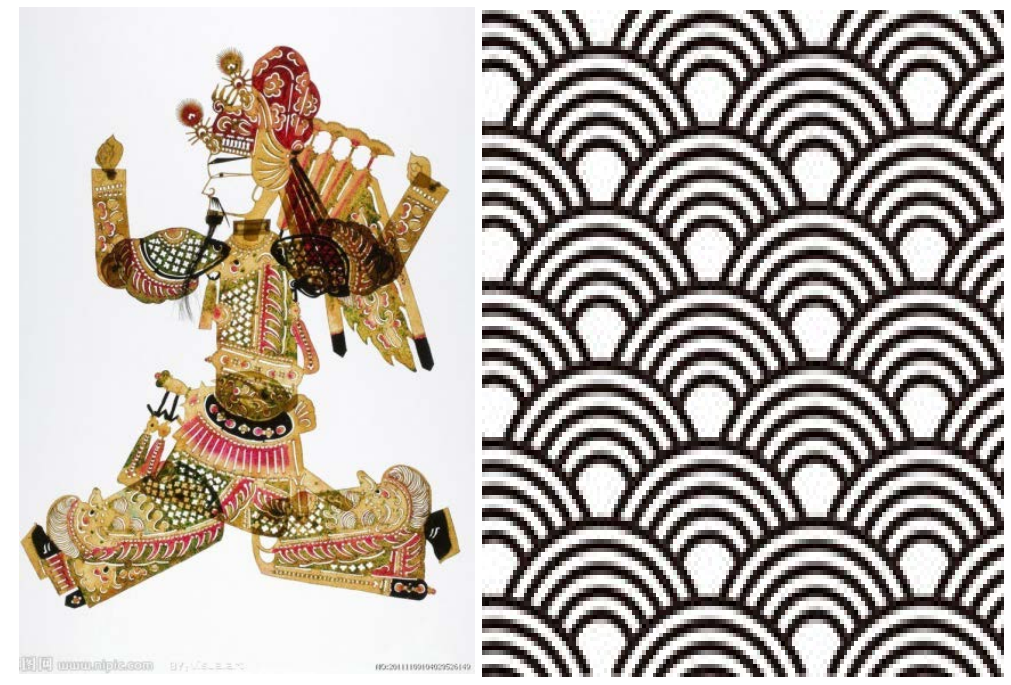

Figure 2. Shadow Play Character (Left) and Shadow Play Pattern (Right)

\section{Conclusion}

Shadow Play has a long history, but as time goes by, there are fewer people who know and even learn about the art. Applying Shadow Play on children's wear can be regarded as a heritage, so children can understand the spread of traditional Chinese culture at a young age. At the same time, producing this clothes and even creating brands has become unique children's clothing with Chinese elements. This clothing not only connects with Chinese culture, but also is closely combined with fashion.

\section{References}

Butler, C. (2010). Modern Women (p. 17). New York: The museum of Modern Art. Cally, B. (2012). 100 Years of Fashion (p. 20). Laurence King Publishers.

Claire, B. S. (1993). Couture Sewing Techniques (p. 23). Connecticut: The Taunton Press.

Jun, N. (2008). Practice of clothing brand enterprises (p. 34). Beijing: China textile publishing house.

Li, X. Y. (2008). Clothing modeling design (pp. 18-20). Shanghai: Shanghai textile industry school.

Liu, X. B. (1996). Design of children's wear (p. 9). Shanghai: donghua university press.

Liu, Y. M. (2001). Stereoscopic tailoring technique (pp. 26-30). Beijing: golden shield press.

Wang, Q. Z. (2008). Reconstruction of fabric design (p. 28). Southwest normal university press.

Yin, D. B. (2006). Introduction to design theory (pp. 18-19). Hengyang: Human science and technology press.

Zhou, L. Y. (2003). Series of children's wear design (p. 6). Beijing: China textile publishing house. 